\title{
STRATEGI PENGEMBANGAN KAWASAN EKOWISATA TEPIAN SUNGAI TALLO DI MAKASSAR
}

\author{
Andi Muhammad Ikhsan ${ }^{1}$ \\ ${ }^{1}$ Jurusan Arsitektur Universitas Muslim Indonesia
}

\begin{abstract}
Abstrak
Kawasan sungai tallo merupakan kawasan dengan perpaduan daerah daratan dengan daerah perairan. Kawasan sungai tallo juga memiliki perpaduan fungsi antara fungsi utama sebagai penyedia air irigasi dan fungsi sebagai daerah tujuan wisata alternatif. Berkaitan dengan hal tersebut wisata yang dikembangkan di kawasan sungai tallo haruslah wisata yang dapat mendukung fungsi utama sungai sebagai penyedia air irigasi dan mendukung konservasi tanah.

Ekowisata (ecotourism) merupakan jenis wisata yang mendukung upaya konservasi. Wisata ini juga memberikan apresiasi yang tinggi terhadap lingkungan, budaya, sejarah dan partisipasi penduduk lokal. Pengembangan ekowisata di kawasan sungai tallo dilaksanakan sebagai upaya pengembangan wisata yang dapat mendukung kelestarian sungai

Penelitian ini bertujuan; (1) Mengidentifikasi potensi ekowisata sungai di kawasan sungai tallo, (2) Merumuskan strategi yang harus dikembangkan dalam pemanfaatan sungai tallo untuk pengembangan ekowisata di Kota Makassar.

Penelitian ini bersifat deskriptif. Pengumpulan data dilakukan melalui observasi, wawancara, dan dokumentasi. Data dianalisis melalui analisis kualitatif.

Hasil penelitian menunjukkan bahwa strategi untuk mengembangkan potensi alam berupa kampung ekologis dan taman ramah lingkungan, menambah akses dari dan menuju ke sungai tallo seperti pembuatan dermaga wisata spermonde, menciptakan lapangan kerja yang sesuai dengan keperluan ekowisata di sungai tallo, perlu dilakukan penelitian lanjutan khususnya mengenai ekohidrolika dikawasan sungai.
\end{abstract}

Kata kunci: sungai tallo, potensi alam, pengembangan ekowisata

\begin{abstract}
The tallo river area is a combination of land and water territories. Tallo river area also has multiple functions, such as irrigation water supplier and alternative tourism destination. Related to that, the tourism concept developed in tallo river area must be the one that can support the main functions of the river as an irrigation water supplier and support land conservation.

Ecotourism is a tourism concept that supports conservation efforts. This kind of tourism highly appreciate historical and cultural environment, also local inhabitants participation. Ecotourism development in tallo river area is conducted as an effort to expand tourism that can support the river's preservation.

The aims of the research are to (1) find out the potency ecotourism area in Tallo riverside, (2) formulate the developed strategy to make use of Tallo River the development of ecotourism in makassar city.

The research was a descriptive study. The methods of obtaining the data were observation, interviews and documentation. The data were analyzed qualitative.

The results of the research reveal that the strategies to develop natural potency are to build ecological village and environmental friendly garden, to improve accessibility in the tallo riverside such as to build spermonde tourism piers, and to provide vocation that is in accordance with ecotourism needs in Tallo River. Further research needs doing especially eco-hydraulics in river areas.
\end{abstract}

Keywords: tallo riverside, natural potency, ecotourism development

\section{PENDAHULUAN}

Kota Makassar sebagai Ibukota Propinsi Sulawesi Selatan lebih menggalakkan usaha pengembangan potensi wisata yang ada. Salah satu sumber daya wisata yang sangat potensial yakni wilayah tepian sungai yang mempunyai kekayaan dan keragaman tinggi dalam berbagai bentuk alam, struktur sejarah, adat, budaya dan berbagai sumberdaya yang lain yang terkait dengan pengembangan kepariwisataan. Kekayaan alam dan lingkungan sekitarnya dengan berbagai keragaman yang tinggi seperti wilayah tepian sungai yang mempunyai nilai atraktif yang wajib dikelola dan dikembangkan bagi kesejahteraan masyarakat melalui pariwisata bahari. Keragaman daerah aliran sungai untuk pariwisata bahari berupa bentuk alamnya dan juga keterkaitan ekologisnya yang 
dapat menarik minat wisatawan baik untuk bermain, bersantai atau sekedar menikmati pemandangan.

Sungai Tallo yang melintas di tengah Kota Makassar memegang peranan penting bagi kawasan Mamminasata, letak Sungai Tallo yang melintasi pusat kota sangatlah strategis, Kawasan Metropolitan Mamminasata diarahkan sebagai pusat pengembangan wilayah Indonesia bagian Timur yang memerlukan penanganan komprehensif sehingga pembangunan yang akan terjadi dapat mendukung sasaran untuk menjadikan Makassar sebagai Pusat Pengembangan Wilayah Indonesia Bagian Timur. Rencana Tata Ruang Kawasan Metropolitan Mamminasata (2003-2012) telah dirumuskan oleh pemerintah Provinsi Sulawesi Selatan, yang bertujuan untuk menciptakan pemanfaatan ruang yang lebih optimal melalui sinergi aspek-aspek sosial, ekonomi, dan lingkungan serta mendorong pemberdayaan manusia yang berwawasan global dan kearifan lokal.

Bertitik tolak pada kondisi obyektif diatas dan potensi ekologi sungai, maka perlu dilakukan suatu kajian untuk melakukan pengembangan kawasan ekowisata di tepian sungai tallo di Kota Makassar. Dengan demikian masyarakat akan terserap dalam kegiatan ekowisata yang banyak memerlukan pelayanan dan dapat dilakukan oleh masyarakat lokal. Pengembangan ekowisata dalam perspektif alternative tourism pada kawasan sungai tallo pada tahap awal seolah-olah mengurangi kendali pemerintah terhadap kawasan sungai. Namun partisipasi masyarakat yang sangat besar, justru mengurangi beban pemerintah dalam pembinaan dan pelestarian lingkungan. Dalam jangka panjang peran pemerintah lebih besar pada fungsi koordinasi dan pembinaan.

Menurut Tukiyat (2002), strategi adalah penempatan sumber daya secara organisir untuk mencapai tujuan, sedangkan taktik adalah sejumlah metode-metode yang dirinci untuk mengalokasikan sumber daya dalam menjalankan rencana strategis. Dalam pengertian ini penjabaran operasional jangka pendek dari sebuah strategi agar dapat diterapkan. Dengan kata lain bahwa strategi menyangkut tentang penentuan aktifitas apa yang seharusnya dikerjakan.

Pada pendekatan lain Tukiyat (2002), memberikan penjabaran bahwa strategi pengembangan ekonomi wilayah merupakan usaha mengembangkan dan meningkatkan hubungan interdefendensi dana interaksi antara sistem ekonomi, sistem masyarakat, lingkungan hidup, dan sumber daya alam. Dengan demikian, strategi dan kebijakan pengembangan Kawasan Ekowisata di Sungai Tallo yang akan dilakukan haruslah berdasarkan pada potensi, kondisi, struktur dan nilainilai budaya masyarakat yang ada.

Menurut Maryono (2005) sungai adalah wadah jaringan pengaliran air mulai dari air mata sampai muara dengan dibatasi kanan dan kirinya sepanjang pengalirannya oleh sempadan, suharti (2004) mendefinisikan tepian sungai sebagai lahan pada kedua sisi di sepanjang palung sungai dihitung dari tepi sampai dengan kaki tanggul sebelah dalam.

Oleh karena itu tepian Sungai Tallo sangat memungkinkan untuk dilakukan penataan ruang dan dengan memperhatikan fungsi sebagai penyangga ekologi, sosial dan ekonomi sebab perkembangan ekonomi dapat diasosiasikan dengan masalah lingkungan yang muncul pada tepian atau bantaran sungai itu sendiri. Beberapa masalah tersebut berhubungan dengan urbanisasi, perubahan yang cepat dalam menggunakan lahan sehingga terjadi pengurangan ruang terbuka hijau, juga ketidak seimbangan suplai air, banjir, erosi tanah, sedimentasi sungai dan lain-lain (Al Mamun et al, 1999).

Ecotourism is responsible travel to natural areas that conserves the environment and improved the well being of local people (Hadi, 2007). Selanjutnya Hadi (2007) menyatakan bahwa prinsipprinsip ekowisata adalah meminimalkan dampak, menumbuhkan kesadaraan lingkungan dan budaya, memberikan pengalaman positif baik kepada turis (visitors) maupun penerima (host) dan memberikan manfaat dan keberdayaan masyarakat lokal. Untuk lebih jelas mengenai beberapa pendapat para ahli ecotourisme. World Tourism Organisation (WTO) dan United Nations Environment Program (UNEP) menyatakan "Ecotourism involves traveling to relatively undisturb natural areas with the specific objective of studying, admiring, and enjoying the scenery and its wild plants and animals as well as any existing cultural aspect found in those area"

Menurut The International Ecotourism Society atau TIES (1991), ecotourism adalah perjalanan wisata ke wilayah-wilayah alami dalam rangka mengkonservasi atau menyelamatkan lingkungan dan member penghidupan penduduk lokal. Menurut World Conservation Union (WCU), ecotourism adalah perjalanan wisata ke wilayah-wilayah yang lingkungan alamnya masih asli, dengan menghargai warisan budaya dan alamnya, mendukung upayaupaya konservasi, tidak menghasilkan dampak negatif, dan memberikan keuntungan sosial ekonomi serta menghargai partisipasi penduduk lokal.

Berdasarkan teori diatas pengembangan kawasan ekowisata di Sungai Tallo ini kemudian merupakan suatu perpaduan dari berbagai minat yang tumbuh dari keprihatinan terhadap lingkungan, ekonomi dan sosial. Ekowisata tidak dapat dipisahkan dengan konservasi.

\section{ISI PENELITIAN}

\subsection{Metode Penelitian}

Tipe penelitian yang digunakan dalam penelitian ini adalah penelitian kualitatif deskriptif, yaitu penelitian yang bermaksud mengidentifikasi potensi ekowisata sungai di kawasan sungai tallo dan merumuskan strategi apa yang harus 
dikembangkan dalam pemanfaatan sungai tallo untuk pengembangan ekowisata di Kota Makassar.

Penelitian kualitatif dikenal dengan cara pengumpulan data yang lazim, yaitu melalui studi pustaka dan studi lapangan. Studi pustaka dilakukan dengan cara mengkaji sumber tertulis seperti dokumen, laporan tahunan, peraturan perundangan, dan diploma/sertifikat. Sumber tertulis ini dapat berupa data primer maupun sekunder, sehingga data yang didapatkan juga dapat berupa data primer maupun sekunder.

Data-data yang didapatkan di dalam penelitian ini adalah berupa data primer dan data sekunder. Pengumpulan data dilakukan dengan cara observasi lapangan, interview dengan semua pengampu kebijakan, telaah dokumentasi, telaah data sekunder dan studi literatur.

Setelah melakukan pengumpulan data maka selanjutnya adalah proses analisis data. Analisis data merupakan upaya mencari dan menata data secara sistematis untuk meningkatkan pemahaman peneliti tentang kasus yang diteliti dan menyajikannya sebagai temuan bagi orang lain. Proses analisis data dalam penelitian kualitatif dimulai dengan menelaah seluruh data yang terkumpul dari berbagai sumber, yaitu dari wawancara, pengamatan yang sudah dituliskan dalam catatan lapangan, dokumen pribadi, dokumen resmi, gambar, foto dan sebagainya (Widoyoko, 2008).

Data-data yang telah didapatkan di lapangan dijelaskan dan dianalisis untuk mendapatkan gambaran (deskripsi) yang aktual terhadap objek yang diteliti. Penyajian data dapat berupa tabel-tabel dan diagram yang dapat menggambarkan kondisi di lokasi penelitian. Kemudian untuk menganalisis strategi digunakan Analisis SWOT, dimana teknik ini adalah salah satu teknik analisis untuk mengkaji kawasan secara keseluruhan. Untuk mengkaji suatu organisasi perlu dilakukan analisis dengan melihat faktor internal (yang muncul dari dalam kawasan) dan faktor eksternal (yang ada atau datang dari luar kawasan).

Kesimpulan penelitian diambil dengan analisis komparatif, yaitu dengan membandingkan data-data yang ditemukan di lapangan. Analisis komparatif adalah analisis mencari kemungkinan hubungan sebab akibat dengan cara mengamati keadaan yang sekarang ada dan mencoba mencari kemungkinan sebabnya dari data yang dikumpulkan (Alfiandra, 2009).

\subsection{Hasil}

Eksisting kawasan konservasi Sungai Tallo saat ini di dominasi oleh tambak / kolam ikan dan daerah rawa (88\%), serta beberapa lahan yang belum diusahakan secara maksimal. Di wilayah studi ini, hanya terdapat 1 kelompok permukiman di Pulau Lakkang, yang merupakan Delta Sungai Tallo, meskipun dengan persentase yang relatif kecil (7\%). Selain tambak dan permukiman, di kawasan ini juga terdapat sawah tadah hujan, hutan mangrove, dan juga bangunan fasilitas umum.

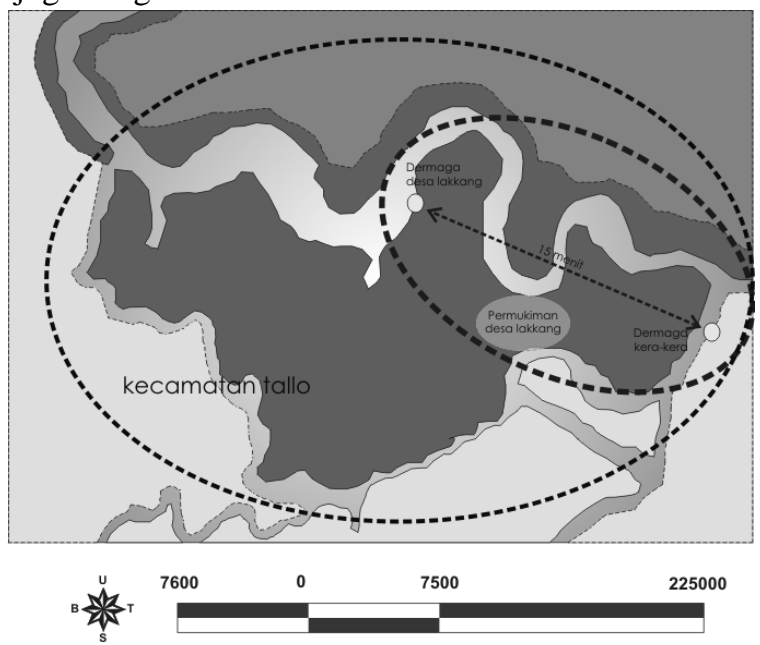

Gambar 1. Peta wilayah penelitian

Sumber : Redrawing peta RTRW Kota Makassar

Berdasarkan Peraturan Pemerintah Nomor 16 Tahun 2004 tentang Penatagunaan Tanah pasal 16, bahwa penggunaan dan pemafaatan tanah pada pulau-pulau kecil dan bidang-bidang tanah yang berada di sempadan pantai, sempadan danau, sempadan waduk dan atau sempadan sungai harus memperhatikan : a. Kepentingan umum. b. Keterbatasan daya dukung, pembangunan berkelanjutan, keterkaitan ekosistem, keaneka ragaman hayati serta kelestaraian fungsi lingkungan. Muara sungai Tallo merupakan daerah bergelombang dengan tambak-tambak ikan dan udang. Penduduknya tinggal didaerah yang tersebar disekitar muara sungai dari kelompok masyarakat itu sendiri. Gaya hidupnya mandiri dengan beban rendah pada lingkungan. Muara sungai tersebut terjaga lingkungan alaminya dengan hutan-hutan bakau dan pohon nipah.

Sungai tallo dalam RTR Terpadu Mamminasata berada di dalam kawasan kendali dalam zona urban,dimana sebagian besar kegiatan pembangunan diatur terkecuali untuk tujuan pendidikan atau sosial sampai pada skala pembangunan tertentu,sesuai dengan pedoman tata guna lahan.

Konservasi lingkungan perkotaan adalah salah satu prioritas utama dalam Perencanaan Tata Ruang Maminasata. Untuk mewujudkan konsep ini, kawasan rawa yang membentang di Sungai Tallo diusulkan untuk dilindungi. Konservasi kawasan rawa tersebut akan memberikan kontribusi terhadap perluasan ruang-ruang hijau di Kota Makasar dan menjadikannya pusat kawasan hijau bagi masyarakat Makassar dan Maminasata.

\subsection{Pembahasan}

Wilayah sebelah Utara dan Selatan Sungai Tallo adalah lahan basah rawa yang diperuntukan warga untuk tambak ikan. Konservasi lahan basah rawa ini cocok ditanami Avicennia Marina atau "Kayu api- 
api“ yang merupakan tanaman bakau/mangrove. Keberadaan tanaman ini akan mendukung usaha tambak, saat bertelur dan membesarkan anakanaknya ikan akan berlindung dibawah perakaran bakau.

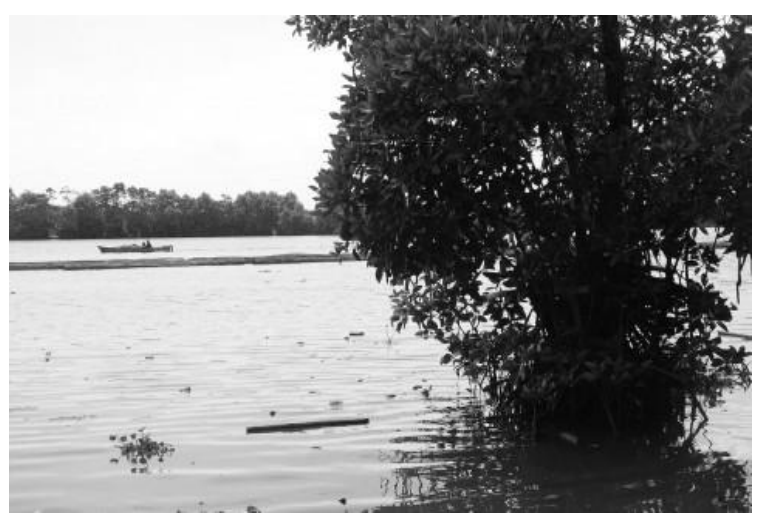

Gambar 2. Pohon Bakau Sungai Tallo

Sumber : Survey April 2012

Tumbuhan mangrove memiliki daya adaptasi yang khas untuk dapat terus hidup. Daya adaptasi tersebut meliputi :

1.Perakaran yang pendek dan melebar luas ,dengan akar penyangga atau tudung akar yang tumbuh dari batang dan dahan sehingga menjamin kokohnya batang.

2. Berdaun kuat dan mengandung banyak air.

3. Mempunyai jaringan internal penyimpan air dan konsentrasi garam yang tinggi.

Di wilayah tepian sungai tallo hampir mayoritas di tumbuhi tanaman Nipah dengan Nama ilmiahnya adalah Nypah fruticans, dan diketahui sebagai salah satunya anggota marga Nypa. Tumbuhan ini merupakan satu-satunya jenis palma dari wilayah mangrove.

Bunga nipah jantan dilindungi oleh seludang bunga, namun yang terisi serbuk sari tetap tersembul keluar. Bunga nipah betina berbentuk bulat peluru dan bengkok mengarah kesamping. Panjang tangkai badan bunga mencapai $100-170 \mathrm{~cm}$. tandan bunga inilah yang dapat disadap untuk diambil niranya. 4 5 bulan sejak keluarnya bunga nipah, tandan bunga tersebut dapat disadap.

Pada saat ini pengisisan biji sedang aktif, maka bila dilakukan penyadapan pasti akan dapat memperoleh jumlah nira yang maksimal. Nipah merupakan salah satu spesies utama penyusun hutan mangrove dengan komposisi sekitar $30 \%$, Rata-rata setiap pelepah nipah menghasilkan nira sebanyak 0,5 per hari.

Jumlah pohon nipah yang efektif adalah 3000 pohon per hektar dan semakin rapat maka pohon nipah tidak akan menghasilkan mayang. Dalam suatu lahan pun biasanya tidak $100 \%$ pohon nipah menghasilkan mayang, biasanya sekitar $40 \%$ saja.

Ekosistem mangrove adalah salah satu ekosistem yang produktifitasnya tinggi. Sehinggga mangrove memberikan kontribusi besar terhadap detritus organik yang sangat penting sebagai sumber energi bagi biota atau Fauna yang hidup di sekitar sungai.

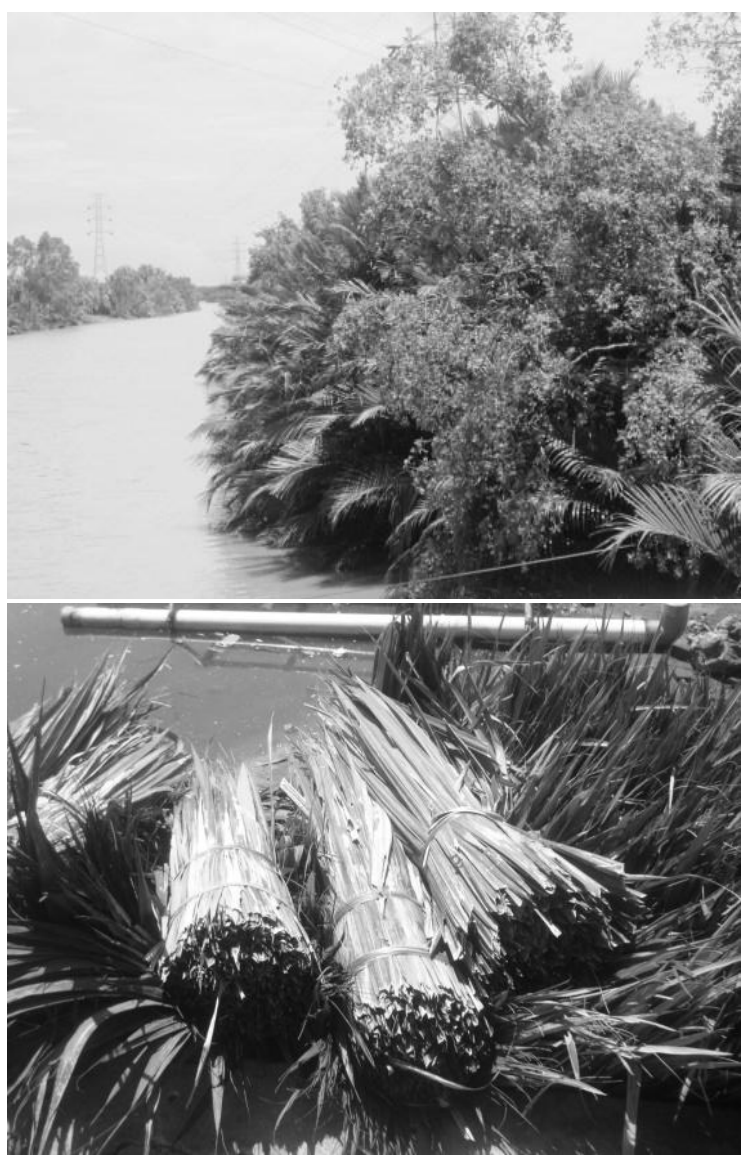

Gambar 3. Pohon Nipah Sungai Tallo

Sumber : Survey April 2012

Komunitas Fauna Mangrove membentuk pencampuran diantaranya adalah :

1. Kelompok fauna daratan / terrestrial (aboreal) yang umumnya menempati bagian atas pohon mangrove, terdiri atas : insekta, ular, primate, dan burung. Kelompok ini tidak mempunyai sifat adaptasi khusus untuk hidup didalam hutan mangrove, karena mereka melewatkan sebagian besar hidupnya di luar jangkauan air laut pada bagian pohon yang tinggi, meskipun mereka dapat mengumpulkan makanannya berupa hewan lautan pada saat air surut.

Jenis burung yang ada di sungai tallo adalah: burung gelatik, burung pipit dada putih, burung gereja, burung kutilang, wallet, dan bangau putih.

2. Kelompok fauna perairan/akuatik, terdiri atas dua tipe, yaitu:

a. Yang hidup dikolam air, terutama berbagai jenis ikan seperti Ikan Nila,ikan gurame, lele dan udang.

b. Yang menempati substrat baik kerasn (akar dan batang pohon mangrove) maupun lunak 
(lumpur), terutama kepiting, kerang dan berbagai jenis avertebrata lainnya.

Wilayah penelitian kawasan konservasi Sungai Tallo - Makassar terletak di bagian Timur Kota Makassar. Wilayah ini berjarak sekitar 5 hingga 17 km dari Kota Makassar. Dari pengamatan lapangan, diketahui bahwa sebagian besar wilayahnya telah dapat dilalui kendaraan bermotor roda 4 atau lebih sepanjang tahun. Saat ini hanya Desa Lakkang, yang terletak di bagian Utara kawasan penelitian yang belum dapat dilalui kendaraan roda 4. Jaraknya yang relatif dekat dengan Kota Makassar, serta dukungan jaringan jalan yang cukup memadai, menjadikan wilayah penelitian cukup mudah dicapai dari berbagai bagian kota lainnya. Rata-rata waktu tempuh ke wilayah ini dari pusat kota hanya sekitar 30 menit. Hanya Desa Lakkang, di bagian Utara kawasan penelitian, yang mengandalkan Sungai Tallo sebagai sarana transportasi, aksesibilitas ke bagian kota lain relatif lebih sulit.

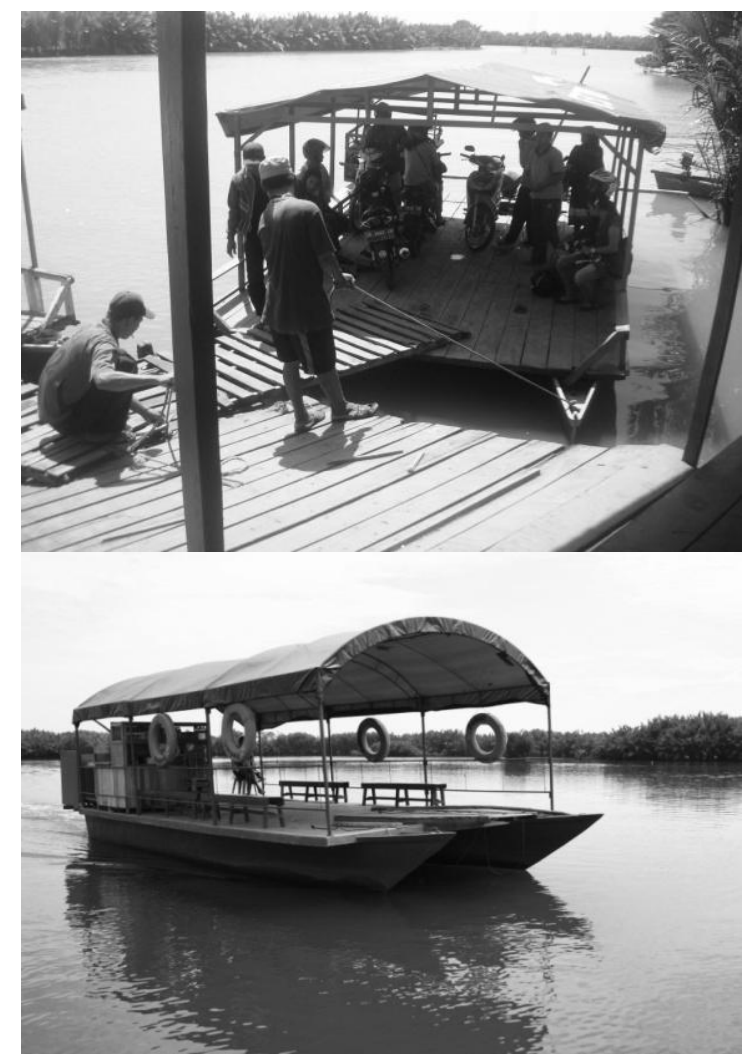

Gambar .4 Transportasi Air

Sumber : Survey April 2012

Analisis berdasarkan potensi kawasan, diarahkan terhadap perumusan hasil analisis pengembangan yang lebih terarah, sehubungan dengan katakteristik fisik kawasan serta potensi sumber daya yang ada lebih mengarah pada potensi kawasan. Adapun potensi yang dimiliki kawasan Sungai Tallo adalah: berdasarkan dalam rencana tata ruang wilayah perkotaan yang ada, maupun rencana wilayah yang lebih luas, disebutkan bahwa wilayah penelitian difungsikan sebagai kawasan konservasi Adapun Peraturan Daerah Kota Makassar Nomor 6 Tahun 2006 tentang RTRW Kota Makassar mengarahkan wilayah studi sebagai Kawasan Penelitian Terpadu, yaitu Kawasan Terpadu yang diarahkan dan diperuntukkan sebagai kawasan dengan pemusatan dan pengembangan berbagai kegiatan penelitian yang dilengkapi dengan kegiatan-kegiatan penunjang yang lengkap yang saling bersinergi dalam satu sistem ruang yang solid; Sebagai kawasan penelitian terpadu, fungsi yang akan dikembangkan di wilayah ini adalah :

1. Pusat Penelitian dan Pengembangan Ilmu Pengetahuan dan Teknologi yang terpadu untuk memenuhi percepatan pembangunan dalam usaha untuk menguasai teknologi unggulan khususnya bidang maritim dan agropolitan.

2. Permukiman berkepadatan rendah, sarana wisata berwawasan lingkungan, sarana bisnis berwawasan lingkungan dan sarana wisata dan olahraga air sebagai pendukung dan pelengkap kegiatan utama;

3. kawasan-kawasan sektor informal yang prospektif dan berdaya tarik tinggi pada lokasilokasi yang mendukung terwujudnya Kota Makassar yang nyaman dan teratur.

4. Kawasan Hijau :

- Ruang Terbuka Hijau Lindung Pengembangan kawasan hijau lindung sebagai kawasan hutan bakau dan area pembibitan mangrove;

- Kawasan hijau Binaan ditargetkan sebesar $55 \%$ (lima puluh lima persen) dari luas kawasan.

Untuk menjadikan kawasan Sungai Tallo sebagai Kawasan Ekowisata yang berpotensi dimasa mendatang, maka perlu diperhatikan kebutuhankebutuhan para pengunjung/wisatawan yang melakukan kegiatan wisata dalam hal ini sarana dan prasarana yang memadai pada kawasan tersebut.

Dalam rangka melakukan pengembangan kawasan ekowisata sungai tallo, adapun faktorfaktor kekuatan yang mendukung dalam pengembangan kawasan ekowisata di sungai tallo adalah:

1. Memiliki Keindahan alam yang menarik seperti Hutan Mangrove, Nipah, Burung burung gelatik, burung pipit dada putih, burung gereja, burung kutilang, wallet, dan bangau putih, dan Jenis Ikan air tawar.

2. Aksesibilitas kawasan dapat diakses melalui beberapa simpul dermaga yang diantaranya dermaga kera-kera dan dermaga rappokalling

Sesuai dengan hasil analisis swot maka dapat dirumuskan proritas utama strategi pengembangan kawasan ekowisata sungai tallo adalah sebagai berikut:

1. Mengembangkan potensi alam berupa kampung ekologis dan taman ramah lingkungan. 
2. Menambah akses dari dan menuju ke Sungai Tallo seperti pembuatan dermaga wisata spermonde.

3. Menciptakan lapangan kerja yang sesuai dengan keperluan ekowisata di Sungai Tallo.

4. Perlu dilakukan penelitian khususnya mengenai Ekohidrolika dikawasan sungai.

\section{KESIMPULAN}

Kawasan konservasi sungai Tallo Makassar, memiliki fungsi utama sebagai, pengendali banjir, abrasi, erosi, serta kawasan konservasi. Selain itu juga berfungsi sebagai kawasan rekreasi, pusat pendidikan lingkungan, taman ramah lingkungan, dan kampung ramah lingkungan.

Berdasarkan hasil analisis kriteria penilaian potensi kawasan ekowisata sungai tallo yang diantaranya :

1. Memiliki Keindahan alam yang menarik seperti Hutan Mangrove, Nipah, Burung gelatik, burung pipit dada putih, burung gereja, burung kutilang, wallet, dan bangau putih, dan Jenis Ikan air tawar.

2. Aksesibilitas kawasan dapat diakses melalui beberapa simpul dermaga yg tersebar ditengah kota makassar, diantranya dermaga kera-kera dan dermaga rappokalling.

maka dapat dirumuskan proritas utama strategi pengembangan kawasan Ekowista Sungai Tallo adalah sebagai berikut:

1. Mengembangkan potensi alam berupa kampung ekologis dan taman ramah lingkungan.

2. Menambah akses dari dan menuju ke sungai tallo seperti pembuatan dermaga wisata spermonde.

3. Menciptakan lapangan kerja yang sesuai dengan keperluan ekowisata di sungai tallo.

4. Perlu dilakukan penelitian khususnya mengenai Ekohidrolika dikawasan sungai.

Sehubungan dengan pembahasan di atas, maka saran-saran yang perlu disampaikan adalah sebagai berikut :

1. Pembangunan masyarakat dalam hal meningkatkan keterampilan untuk mendukung lapangan kerja dibidang ekowisata.

2. Mendorong peneliti selanjutnya untuk meneliti tentang ekohidrolika dalam pengembangan wisata air khususnya disungai tallo.

\section{DAFTAR PUSTAKA}

- Ann Bren dan Dick Rigby, Waterfront : Cities Reclaim Their Edges, Mc Graw Hill Inc. New York, hal. 10.

- Ardani, 1992. Konsep-konsep pengembangan wilayah.

- Choy,D.L. 1997. Perencanaan Ekowisata. Belajar dari Pengalaman di South East Queesland. Proceedings on The Planning and Workshop of Planning Sustainable Tourism. Penerbit ITB Bandung.
- Damanik, J. dan Weber, H.F. 2006. Perencanaan Ekowisata - Dari Teori ke Aplikasi. Penerbit Andi. Yogyakarta.

- Fandeli,C. Dan Nurdin,M. 2005. Pengembangan Ekowisata Berbasis Konservasi di Taman Nasional. UGM. Yogyakarta.

- Faulkner, B. 1997. Tourism Development in Indonesia, In Big Prespective Proceeding on the Training and Workshop of Planning Sustainable Tourism. Penerbit ITB. Bandung.

- Hadi, S. P. 2007. Pariwisata Berkelanjutan (Sustainable Tourism). Makalah Seminar Sosialisasi Sadar Wisata "Edukasi Sadar Wisata bagi Masyarakat di Semarang.

- Rangkuti, F. 1997. Analisis SWOT : Tehnik Membedah Kasus Bisnis. Gramedia Pustaka Utama. Jakarta.

- Soemarwoto, O. 2004. Ekologi, Lingkungan Hidup dan Pembangunan. Djambatan. Jakarta.

- Wikantari, Ria. 2009. Metode Penelitian. Disajikan sebagai Bahan Ajar pada Mahasiswa Perencanaan Pengembangan wilayah Angkatan 2009, Program Pascasarjana Universitas Hasanuddin Makassar, Makassar 12 Desember 2009 